\title{
Factors which are associated with dental decay in the older individual
}

\author{
W.J. Loesche ${ }^{1,2}$; G.W. Taylor'; I.D Dominguez'; N.S. Grossman' and J. Stoll'

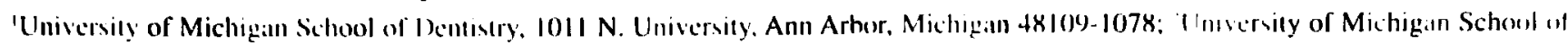 \\ Medicine; 'Ann Arbor Velerans Afliars Medical Center, Ann Arbor, Michuzann
}

\begin{abstract}
Objectives: To improve reliability of salivary bacterial cultures as a surrogate for plaque levels of cariogenic bacterial species by reporting the silivary CFUs of these organisms as a function of the number of teeth. Design: Cross-sectional collection of data in a convenience sample of adults over 60 years of age. Setting: Hospital Dental clinic, University bacteriology laboratory. Subjects: 52.3 older dentate subjects, average age 70. including 412 subjects who were in an independent living status and 111 in al dependent-living situation. Main outcome measures: Subjects were examined for decaly and the presence of salivary factors including the levels of $S$. mutans, lactobacilli, yeast and other bacteria. The salivary levels of the bacteria were adjusted for the number of teeth in the mouth, and the resultant values were entered into multivariable logistic regression models along with clinical and other salivary parameters. Results: Mutans streptococci levels reported as CFUs/ml saliva per tooth were significantly associated with coronal surface decay, and lactobacilli. reported in a similar way, were significantly associated with root surface decay. Salivary levels of yeasts, which had previously been associated with decay in this population, were no longer significant using this construct. Conclusions: This construct of reporting salivary bacteriological data as a function of tooth number and per $\mathrm{ml}$ saliva could improve the reliability of bacteriological data obtained in epidemiological studies investigating the role of bacteria in dental decay in the elderly.
\end{abstract}

Key words: mutans streptococci, lactobacilli, yeasts, dental caries, older adults, rmot surface caries

\section{Introduction}

Most, if not all, forms of dental decay are chronic bacterial infections due to the dominance in the plaques of aciduric bacterial species such as the mutans streptococci and lactobacilli'. Decay, typically manifests itself in the one-to two-year period following the eruption of the teeth and, as such, has been primarily an infection of children and teenagers. Most of the prevention/treatment emphasis has been directed towards these younger individuals, and the demonstration of the involvement of specific aciduric species in the process has been obtained from this age group. It has been assumed that the same bacteriological etiology would apply to decay in adults, especially in the older adult. In general this has been the case, as most investigators have associated the mutans streptococci and the lactobacilli with decay in elderly individuals $\mathrm{s}^{2 \cdot 6}$. However, in the elderly, another aciduric group of organisms, namely yeast, can be associated with decay ${ }^{7-10}$. This suggests that the types of microbes involved in dental decay may be somewhat different in the elderly compared to the young.

The relationship between salivary levels of cariogenic bacteria and caries prevalence and/or incidence is complicated in the elderly because of the confounding effect of many missing teeth, the presence of full and partial dentures, decreased salivary flow, a polypharmacia that could affect salivary flow and taste ${ }^{11.12}$. and thus influence food choices, debilitating diseases such as arthritis which could affect oril hygiene practices, and the constellation of factors associated with a dependent-living status' ${ }^{3}$. For example, the presence of partial or full dentures increases the levels of the mutans streptococci $i^{2.14 .15}$, yearst ${ }^{16.17}$ and 
lactobatcillit.17, and this could influence the interpretation of any relationship between these aciduric species and dental decily. In a previous investigation in which saliva was collected from over 560 ) elderly individuals (average age $70 \pm 8$ $y$ r.). the variables which could influence the bacterial counts/ml of salival, e.g., living status. complaint of xerostomia, stimulated salivary flow, salivary $\mathrm{pH}$, dentures, number of teeth and decay, were analyzed simultaneously using a multivariable linear model ${ }^{10}$. Among the 321 dentate subjects, the number of decayed teeth was significantly associated with lactobacilli $(p=0.0001)$ and yeast $(p=0.025)$, but not with the mutans streptococci. These findings indicated that salivary levels of lactobacilli and yeasts might be better microbial indicators of caries activity in elderly individuals, than would the levels of the mutans streptococci.

The number of teeth in these dentate subjects ranged from 1 to 28 , and as the mutans streptococci live primarily, if not exclusively, on the teeth, the number of teeth could have had a profound influence on the salivary levels of the mutans streptococci. Indeed the salivary levels of the mutans streptococci were positively associated with the number of teeth $(\mathrm{p}<0.0001)$, raising the possibility that this association was so strong in the models, that it overwhelmed any relationship between the mutans streptococci and dental decay. This possibility was evaluated in the present investigation by creating a new set of bacterial variables, in which the CFUs of a bacterial species/ $\mathrm{ml}$ saliva was divided by the number of teeth in the individual, and these new variables were assessed for their relationship to dental decay in these older individuals.

\section{Materials and Methods}

\section{Subjects}

The 523 dentate subjects included the 321 reported on in the earlier study ${ }^{10}$, plus 202 new admissions to our ongoing longitudinal study of the interactions of dental disease with medical disease in the elderly. In order to assess possible effects of living status, we included both independent-living and dependent-living subjects. The independentliving subjects were sampled as they attended a dental outpatient clinic in the Ann Arbor Veteran's Affairs (VA) Medical Center ( $n=221$ ), or who were seen in a dental clinic in a private residential retirement community $(n=191)$. The dependentliving subjects were residents of a long-term care facility in the VA Hospital $(n=67)$, or were recently admitted to an acute care ward of the VA Hospital with a diagnosis of a cerebral vascular accident or other neurological condition ( $n=44)$. All subjects were over 60 years of age (average age was $70.7 \pm 7.9$ years).

\section{Questionnaire}

All participants were interviewed by trained individuals who used a structured questionnaire to elicit information about demographic characteristics, medical and dental history, oral hygiene habits, complaints of a dry mouth (xerostomia), and usage of prescription medications. Some of the questions on xerostomia reportedly reflect actual salivary gland performance $1^{18}$, and these questions were again asked by the dentist when the subjects had their dental examination. The Kappa statistic for the amount of agreement between the interview and clinical forms concerning questions about xerostomia ranged from 0.65 to 0.74 , indicating substantial agreément between the two responses. For our analysis, only those subjects who answered yes to the xerostomia questions on both occasions were considered as having xerostomia.

\section{Dental Examination}

The same clinician-dental assistant team using the VA dental facility examined all VA patients. A second clinician/dental hygienist team examined all non-VA patients. The number of teeth that were present and the number of decayed/missing/filled teeth and surfaces (DMF teeth. DMF surfaces) were recorded using the criteria described in the national survey of Oral Health of United States Adults $^{19}$. The presence of any fixed or removable prostheses, dentures or implants was recorded.

\section{Saliva}

Whole saliva was stimulated by swabbing the tongue with a $2 \%$ citric acid solution three times at 30 -second intervals ${ }^{20}$. During the next minute the patients swallowed the first flow of saliva containing the citric acid. Thereafter, the stimulated saliva was collected over a 3-or 5-minute period by asking the patients to tilt their head forward and to spit their saliva into a graduated, preweighed conical tube. We used citric acid to stimulate salivary flow, thereby reducing the variability associated with chewing paraffin wax by edentate and partially edentate individuals. We also measured the volume of the saliva gravimetrically so as to minimize reading errors due to the presence of foam ${ }^{3}$. If the patient was unable to provide about $1 \mathrm{ml}$ of saliva after 5 minutes, he/she was given a $10 \mathrm{ml}$ solution of 
sterile $\mathrm{H}_{2} \mathrm{O}$ to rinse, and this was collected and used for the bacteriological studies. Most hospitalized patients had their saliva collected by a suction procedure $^{21}$, as it was difficult for them to spit because of their medical condition.

The amount of saliva, as determined gravimetrically, the length of collection and the time of day of the collection were recorded. All stimulated salivas and rinse solutions were immediately frozen in liquid nitrogen and returned to the laboratory.

\section{Bacteriology}

The logistics of this study required that the saliva samples had to be stored for a certain period of time. The use of liquid nitrogen to preserve bacteriological samples collected in the field could reduce the numbers of CFUs recovered for certain bacterial species. Preliminary studies indicated that Gram positive bacteria, such as the streptococci, were more likely to survive this process. The saliva samples were processed in batches of 10 . They were removed from the liquid nitrogen, thawed at room temperature, the weight of the saliva determined, and then brought into an anaerobic chamber. A $0.5 \mathrm{ml}$ portion of saliva was added to $4.5 \mathrm{ml}$ of reduced transport fluid (RTF), which was then sonified for $20 \mathrm{sec}$. (Kontes Sonifier), serially diluted and automatically plated (Spiral Systems) on a variety of selective media as follows: enriched trypticase soy agar (ETSA) with $2 \%$ sucrose and $20 \mu \mathrm{g} / \mathrm{ml}$ metronidazole which, when incubated anaerobically, permitted, because of the sucrose, the enumeration of the unique colonies of Streptococcus mutans, $S$. sanguis and $S$. salivarius $^{22}$, Lactobacillus selective (LBS) agar which permitted the enumeration of the lactobacilli; TYCSB (Trypticase, yeast extract, cystine, sucrose, bacitracin) agar ${ }^{23}$, which permitted the determination of $S$. mutans and $S$. sobrinus counts; and Sabouraud agar which was incubated aerobically to obtain the yeast count. All agar plates were incubated anaerobically for 7 days except for the overnight aerobic incubation of the Sabouraud plates.

All bacteriological counts were normalized to colony forming units (CFU) per $\mathrm{ml}$ of saliva. For those counts obtained from the rinse, $0.2 \mathrm{ml}$ saliva was used as the default value for the normalization, as this would reflect the amount of saliva that these individuals would produce in one minute. These CFU values per $\mathrm{ml}$ saliva were then divided by the number of teeth present in the individual, so as to obtain the variable of interest, $\mathrm{CFU} / \mathrm{ml}$ saliva/ tooth for each of the monitored organisms.
The remainder of each saliva sample was removed from the chamber and the salivary $\mathrm{pH}$ was determined using a pH meter, or in cases of a very small residual volume, i.c., $<0.1 \mathrm{ml}$, with $\mathrm{pH}$ paper and the buffer capacity was determined with a commercially available kit (I)ento-Buff, Orion Diagnostic Laboratories).

\section{Statistical Analysis}

The numbers of subjects available for the analysis varied due to missing data on some variables. All analyses were performed using SAS. In the present investigation, we examined the effect of living status, rate of salivary flow, use of rinse to collect the samples and other variables on the salivary levels of the aciduric organisms such as $S$. mutans, S. sobrinus, lactobacilli and yeast. We included for comparison purposes, non-aciduric species such as Streptococcus sanguis, a tooth-associated species, and Streptococcus salivarius, a soft tissueassociated species.

The chi-square test was employed to evaluate frequencies of dental decay by living status, and complaints of dry mouth (Tables 1 and 2). Comparisons of salivary bacterial counts as a function of caries status were made using the Kruskal-Wallis Rank-sum non-parametric analog of the analysis of variance ${ }^{24}$. This non-parametric method was utilized because of the skewed distributions for the bacterial counts. Logistic regression models ${ }^{25}$ were developed to assess combined and partial effects of predictors for the caries outcomes (Tables 4-7).

\section{Results}

The $\log$ CFUs of $S$. mutans $/ \mathrm{ml}$ saliva on the TYCSB medium were significantly higher than those obtained from the ETSA-metronidazolesucrose medium, $(3.73 \pm 2.45$ vs $2.43 \pm 2.89, p=$ 0.001 , Kruskal Wallis test). These counts on the TYCSB medium were divided by the number of teeth in the mouth and used in the statistical analysis.

Seventy-eight subjects had so little saliva, i.e., $0.2 \mathrm{ml} / \mathrm{min}$, that a rinse was used to collect the oral bacteria. Fifty four percent of the rinse subjects had decay compared to a $61 \%$ prevalence in the 445 subjects in whom saliva could be collected without the rinse (chi square, $p=0.26$ ). There were no differences in the prevalence of coronal surface decay $(p=0.39)$, or root surface decay $(p=0.44)$, between these groups. There was no effect of the use of a rinse on dental decay when this variable was included in the logistic regression models. Because of these findings, the data from the rinse 
group were merged wilh that firom the saliva group in the subseguent andysis.

Decill wats more prevalent in dependent-living subjects than in independent-living subjects. Eighty onc percent of the dependent-living subjects had any 19 pe of decaly compared to $54 \%$ af the independent-living subjecls (chi square, $p=0.0001$, lable 1). Seventy percent of the subjects reported a complaint of a dry mouth. This complaint was statistically alssocialted with any lype of decay and coronal surlace decaly, but narrowly missed being significant for root surface decay (Table 2).

All monitored species, with the exception of $\mathrm{S}$. solivarius. Were significantly associated with any ly pe of decay. coronal surface decay and root surface decay when the bacterial counts were reported as log CFU/ml saliva/tooth (Table 3). The negative numbers for $S$. sobrinus and $S$. salivarius reflect that after dividing by the number of teeth, values less than $10 \mathrm{CFU}$ were obtained.

This series of two-way analyses presented in Tables $1-3$ showed the significant associations for dependent-living status, complaint of dry mouth and various bacterial variables on the prevalence of decay. None of the other monitored variables, i.e., presence of any type of dentures, salivary $\mathrm{pH}$, and stimulated salivary flow, had any significant association with caries.

All of the parameters were examined simulaneously using multivariable logistic regression (Table 4-6). The 'full' model for the presence of any decay showed $S$. mutans and a dependent living state to be positively associated, while being female was negatively associated, with the presence of either coronal surface or root surface decay (Table 4). These variables, plus those with a $\mathrm{p} \leq 0.25$ in the full model, were introduced into a reduced model. $S$. mutans, the lactobacilli and a dependent-living status were positively associated with any type of decay, whereas being female or black were negatively associated.

The modelling procedure was used to determine which factors would be significant when only 'coronal' decay was considered. The results were almost identical to the 'any' decay model with $S$. mutans levels and a dependent-living status being

Table 1. Effect of lising status on prevalence of dental decay

\begin{tabular}{|c|c|c|c|}
\hline \multirow[b]{2}{*}{ Presence of } & \multicolumn{2}{|c|}{ Living status } & \multirow[b]{2}{*}{$\begin{array}{c}\text { Significance } \\
\chi^{2}\end{array}$} \\
\hline & $\begin{array}{c}\text { Independent } \\
\text { ( } \mathrm{n}=412 \text { subjects) }\end{array}$ & $\begin{array}{c}\text { Dependent } \\
\text { ( } \mathrm{n}=111 \text { subjects) }\end{array}$ & \\
\hline \multicolumn{4}{|l|}{ Any decay } \\
\hline No & 190 & 21 & $p=0.0001$ \\
\hline Yes & $222(5+\%)$ & $90(81 \%)$ & \\
\hline \multicolumn{4}{|c|}{ Coronal surface deciy } \\
\hline No & $23(1$ & 25 & $p=0.0001$ \\
\hline Yes & $18 \geq(4+4 \%)$ & $86(77 \%)$ & \\
\hline \multicolumn{4}{|c|}{ Root rurface decay } \\
\hline No & 288 & 61 & $p=0.0001$ \\
\hline Yes & $124(30 \%)$ & $50(45 \%)$ & \\
\hline
\end{tabular}

Table 2. Effect of a complaint of a dry mouth on prevalence of decialy

\begin{tabular}{|c|c|c|c|}
\hline \multirow[b]{2}{*}{ Presence of } & \multicolumn{2}{|c|}{ Complaint of a dry mouth } & \multirow[b]{2}{*}{$\begin{array}{c}\text { Significance } \\
\chi^{2}\end{array}$} \\
\hline & $\begin{array}{c}N_{1} \\
(n=1+8 \text { subjects })\end{array}$ & $\begin{array}{c}\text { Yes } \\
(\mathrm{n}=347 \text { subjects) }\end{array}$ & \\
\hline \multicolumn{4}{|l|}{ An! decay } \\
\hline$N_{1}$ & 71 & 140 & \multirow[t]{2}{*}{$p=0.03$} \\
\hline Yes & $77(52 \%)$ & $23+\left(66^{\prime} i\right)$ & \\
\hline \multicolumn{4}{|c|}{ Coronal Surface Decay } \\
\hline No & 83 & 172 & \multirow[t]{2}{*}{$p=0.04$} \\
\hline Yes & $65(44 \%)$ & $202(5+\%)$ & \\
\hline \multicolumn{4}{|c|}{ Root Surtace Decay } \\
\hline No & 108 & $2+1$ & \multirow[t]{2}{*}{$p=0.06$} \\
\hline Yes & $4(1)(27 \%)$ & $133(36 \%)$ & \\
\hline
\end{tabular}


positively associated with, and being female or black being negatively associated with 'coronal' decay (Table 5). The model for root surface decay, however, showed lactobacilli, being older, and wearing any type of denture to be positively associated with decay and being female to be negatively associated with decay.

These findings are summarized in Table 7. The salivary levels of $S$. mutans after dividing by the number of teeth were significantly asssociated with any deciay and coronal surface decay. The salivary levels of lactobacilli after dividing by the number of teeth were significantly associated with any decay and root surliace decay. Females were 2.9 times less likely to have any type of decay, 4.35 times less likely to coronal surface decay, and 2.3 times less likely to have root surface decay than a male. Individuals who were black were 2.38 times

Table 3. Relationship between salivary levels (median values) of certain oral bacteria and types of decay in older individuals

\begin{tabular}{lcccccc}
\hline Log CFU/ml/Tooth & \multicolumn{2}{c}{ Any decay } & \multicolumn{2}{c}{ Coronal decay } & \multicolumn{2}{c}{ Root decay } \\
Median Values & $\begin{array}{c}\text { No } \\
(\mathrm{n}=207)\end{array}$ & $\begin{array}{c}\text { Yes } \\
(\mathrm{n}=312)\end{array}$ & $\begin{array}{c}\text { No } \\
(\mathrm{n}=251)\end{array}$ & $\begin{array}{c}\text { Yes } \\
(\mathrm{n}=268)\end{array}$ & $\begin{array}{c}\text { No } \\
(\mathrm{n}=345)\end{array}$ & $\begin{array}{c}\text { Yes } \\
(\mathrm{n}=174)\end{array}$ \\
\hline S. mutans & 3.02 & $3.46^{* *}$ & 3.09 & $3.46^{* *}$ & 3.13 & $3.65^{* *}$ \\
S. sobrinus & -1.36 & $-1.30^{* *}$ & -1.36 & $-1.30^{* *}$ & -1.36 & $-1.28^{* *}$ \\
Lactobacilli sp. & 2.38 & $3.00^{* *}$ & 2.64 & 2.95 & 2.40 & $3.48^{* *}$ \\
Candida sp. & 0.92 & $1.49^{* *}$ & 0.94 & $1.51^{* *}$ & 1.10 & $1.72^{* *}$ \\
S. sanguis & -0.60 & $3.59^{* *}$ & -0.60 & $3.63^{* *}$ & $2.95^{*}$ & $3.55^{*}$ \\
S. salivarius & -1.28 & -1.26 & -1.28 & -1.26 & -1.30 & $-1.23^{*}$ \\
\hline
\end{tabular}

* Significance - Kruskal-Wallis Test $\mathrm{p}<0.05$ to 0.01

** Significance - Kruskal-Wallis Test $\mathrm{p}<0.01$

Table 4. Presence of any dental decay - all subjects ( $n=501$ ). 302 subjects with decay; 99 subjects with no decay

\begin{tabular}{|c|c|c|c|c|}
\hline \multirow[b]{2}{*}{ Variable } & \multicolumn{2}{|c|}{ Full model } & \multicolumn{2}{|c|}{ Reduced model } \\
\hline & $P=$ & Odds ratio & $P=$ & $\begin{array}{c}\text { Odds ratio } \\
\text { (95\%) confidence interval) }\end{array}$ \\
\hline \multicolumn{5}{|c|}{ Log CFUs/ml saliva/tooth } \\
\hline S. mutans & 0.03 & 1.11 & 0.012 & $1.12(1.02-1.21)$ \\
\hline S. sobrinus & 0.76 & 1.30 & & \\
\hline Lactobacilli & 0.17 & 1.07 & 0.036 & $1.09(1.01-1.19)$ \\
\hline Candida & 0.79 & 1.02 & & \\
\hline S. sanguis & 0.38 & 1.03 & & \\
\hline S. salivarius & 0.24 & 0.95 & & \\
\hline Age & 0.98 & 1.00 & & \\
\hline Dentures & 0.70 & 1.09 & & \\
\hline Rinse & 0.41 & 0.73 & & \\
\hline Salivary $\mathrm{pH}>6.5$ & 0.72 & 1.09 & & \\
\hline Dry mouth complaint & 0.18 & 1.39 & & \\
\hline Low salivary flow & 0.93 & 0.98 & & \\
\hline Female & 0.0001 & 0.35 & 0.0001 & $0.34(0.22-0.52)$ \\
\hline White & 0.77 & 0.82 & & \\
\hline Black & 0.18 & 0.37 & 0.007 & $0.42(0.23-0.79)$ \\
\hline \multirow[t]{4}{*}{ Dependent Living } & 0.0005 & 3.24 & 0.0001 & $3.79(2.08-6.90)$ \\
\hline & \multicolumn{2}{|c|}{ Chi square $=68.5$} & \multicolumn{2}{|c|}{ Chi square $=83.5$} \\
\hline & \multicolumn{2}{|c|}{$P=0.001$} & \multicolumn{2}{|c|}{$P=0.0001$} \\
\hline & \multicolumn{2}{|c|}{$\mathrm{DF}=16$} & $\mathrm{DF}=5$ & \\
\hline
\end{tabular}


less likely 10 any type of deciay and 2.94 times less likely to have coromal surlice decay than other racial groups. Individuals in a dependent-living situation were 3.8 times more likely to have any type of decay and 4.5 times more likely to have coronal surlace decay compared to independentliving individuals. Older individuals and those wearing any type of denture were more likely to have root surface decay than younger individuals and those without dentures.

Table 5. Presence of coronal surfise decay - all subjects. 231 subjects with decay; 209 subjects without decay

\begin{tabular}{|c|c|c|c|c|}
\hline \multirow[b]{2}{*}{ Variable } & \multicolumn{2}{|c|}{ Full model } & \multicolumn{2}{|c|}{ Reduced model } \\
\hline & $P=$ & OR $(95 \% \mathrm{CI})$ & $P=$ & OR \\
\hline \multicolumn{5}{|c|}{ Log CFUs/ml saliva/tooth } \\
\hline s. mutans & 0.03 & 1.11 & 0.01 & $1.12(1.03-1.22)$ \\
\hline S. sobrinus & 0.61 & 1.04 & & \\
\hline Lactobacilli & 0.67 & 0.98 & & \\
\hline Candida & 0.57 & 1.04 & & \\
\hline S. sanguis & 0.10 & 1.07 & & \\
\hline S. salivarius & 0.66 & 0.98 & & \\
\hline Age & 0.14 & 0.98 & & \\
\hline Dentures & 0.57 & 0.88 & & \\
\hline Salivary $\mathrm{pH}>6.5$ & 0.46 & 1.19 & & \\
\hline Dry mouth complaint & 0.13 & 1.47 & & \\
\hline Low salivary flow & 0.81 & 1.06 & & \\
\hline Female & 0.0001 & 0.22 & 0.0001 & $0.23(0.14-0.36)$ \\
\hline White & 0.98 & 0.98 & & \\
\hline Black & 0.10 & 0.30 & 0.001 & $0.34(0.18-0.65)$ \\
\hline \multirow[t]{2}{*}{ Dependent living } & 0.0001 & 3.88 & 0.0001 & $4.5(2.58-7.90)$ \\
\hline & \multicolumn{2}{|c|}{$\begin{array}{l}\text { Chi square }=99.17 \\
P=0.0001 \\
D F=15\end{array}$} & \multicolumn{2}{|c|}{$\begin{array}{l}\text { Chi square }=108.3 \\
P=.0001 \\
D F=4\end{array}$} \\
\hline
\end{tabular}

Table 6. Presence of root surface decay - all subjects. 153 subjects with decay: 269 subjects without decay

\begin{tabular}{|c|c|c|c|c|}
\hline \multirow[b]{2}{*}{ Variable } & \multicolumn{2}{|c|}{ Full model } & \multicolumn{2}{|c|}{ Reduced model } \\
\hline & $P=$ & OR $(95 \% \mathrm{CI})$ & $P=$ & OR \\
\hline \multicolumn{5}{|c|}{ Log CFUs/ml saliva/tooth } \\
\hline S. mutans & 0.27 & 1.06 & & \\
\hline S. sobrinus & 0.68 & 1.03 & & \\
\hline Lactobacilli & 0.001 & 1.20 & 0.0001 & $1.24(1.14-1.37)$ \\
\hline Candida & 0.82 & 1.02 & & \\
\hline S. sanguis & 0.45 & 0.97 & & \\
\hline S. salivarius & 0.80 & 0.99 & & \\
\hline Age & 0.002 & 1.05 & 0.004 & $1.04(1.01-1.07)$ \\
\hline Dentures & 0.27 & 1.66 & 0.04 & $1.55(1.02-2.36)$ \\
\hline Rinse & 0.86 & 0.93 & & \\
\hline Salivary pH > 6.5 & 0.80 & 0.94 & & \\
\hline Dry mouth complaint & 0.32 & 1.29 & & \\
\hline Low salivary flow & 0.33 & 1.32 & & \\
\hline Female & 0.004 & 0.42 & 0.002 & $0.43(0.25-0.74)$ \\
\hline White & 0.23 & 0.48 & & \\
\hline Black & 0.23 & 0.43 & & \\
\hline \multirow[t]{2}{*}{ Dependent living } & 0.45 & 1.50 & & \\
\hline & \multicolumn{2}{|c|}{$\begin{array}{l}\text { Chi square }=59.3 \\
P=0.001 \\
D F=16\end{array}$} & \multicolumn{2}{|c|}{$\begin{array}{l}\text { Chi square }=49.7 \\
P=.0001 \\
D F=4\end{array}$} \\
\hline
\end{tabular}


Table 7. Odds ratio for oral/dental parameters which are significantly associated with decay in elderly individuals

\begin{tabular}{lccc}
\hline & Any decay & $\begin{array}{c}\text { Decay } \\
\text { Coronal surface }\end{array}$ & Root surface \\
\hline $\begin{array}{l}\text { Bacteriological } \\
\quad \text { S. mutans* }\end{array}$ & 1.12 & 1.12 & \\
$\begin{array}{l}\text { Lactobacilli sp.* } \\
\text { Dental }\end{array}$ & 1.09 & & 1.24 \\
$\quad$ Dentures & & & 1.55 \\
$\begin{array}{l}\text { Life Style } \\
\quad \text { Dependent living }\end{array}$ & 3.79 & 4.50 & \\
$\begin{array}{l}\text { Demographic } \\
\quad \text { Female } \\
\text { Black }\end{array}$ & -2.90 & -4.35 & -2.30 \\
$\quad$ Age & -2.38 & -2.94 & 1.04 \\
per tooth & & & \\
\hline
\end{tabular}

\section{Discussion}

In recent years several groups have used the salivary levels of mutans streptococci and lactobacilli to identify older individuals at risk to dental decay $y^{2 \cdot 10.27-31}$. The development of diagnostic guidelines for the levels of these species was based on data obtained in children and young adults, where the rate of stimulated saliva is almost always above $0.5 \mathrm{ml} / \mathrm{min}^{14 .}{ }^{26}$, and the contribution of the teeth to the bacterial load of the saliva would be relatively constant because most, if not all, of the teeth would be present. But these conditions are not met in the elderly, as many teeth are missing, many individuals wear dentures, and salivary flow is often reduced secondary to the usage of medications ${ }^{11.12 .16}$. Both missing teeth and dentures could confound the interpretation of salivary levels of these bacteria, as missing teeth lowers the levels of the mutans streptococci ${ }^{10}$, and the wearing of either partial or complete dentures increases the salivary levels of the mutans streptococci ${ }^{10,15.17}$ and lactobacilli2.31.32. Missing teeth, complaints of xerostomia' ${ }^{12}$ and reduced salivary flow would affect food choices, which could further affect the bacteriological composition of the saliva.

When we previously used a multivariable linear model to analyze several of those variables, which could affect the levels of the mutans streptococci per ml of saliva, there was no association in older individuals between the presence of dental decay and the mutans streptococci ${ }^{10}$. Rather, the levels of other aciduric species such as the lactobacilli and yeasts were significantly related to the presence of decay. The absence of any significant association in the elderly between decay and $S$. mutans was unexpected, as other studies in older individuals have shown a strong positive association of high

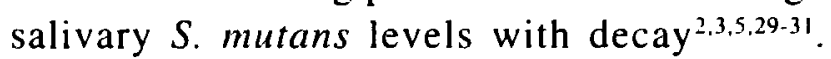
However, some investigators have also been unable to associate the mutans streptococci with decay, but were able to associate lactobacilli and/or yeasts with decay $7.9,27,28,30$.

These equivocal findings suggest that the bacterial factors in dental decay in the elderly, which would include root surface decay, might be different than in the young. But they could mean that the methods used to measure the salivary levels of the mutans streptococci, that were developed in young individuals, do not completely transfer to the elderly, because of the presence of missing teeth, dentures, and xerostomia, among other confounders. For instance, the chewing of paraffin wax to obtain stimulated saliva may yield salivas of different microbial compositions for individuals with a full dentition compared to individuals with missing teeth and any type of denture. In the present study saliva was collected after citric acid stimulation because of the concern that some of our subjects might aspirate the wax. Another study which used citric acid stimulated saliva could not find a relationship between salivary levels of the mutans streptococci and decay among older subjects ${ }^{27}$. In fact, there is so much variability related to saliva collection ${ }^{33}$, that this could explain some of the bacteriological differences observed between studies.

The relationship between dental decay and the mutans streptococci were established using plaque cultures'. Salivary cultures are a surrogate for plaque samples, and the fidelity of the statistical relationship between the mutans streptococci and decay decreases, as one moves from single plaque 
samples, to pooled plaque samples, to saliva samples ${ }^{4}$. This concern has recently been documented with root surface decay, where the plaque over the lesion may not aceurately reflect the kevels of lactobacilli within the lesion"s. Another reduction in fidelity would occur when commercially manufactured kits containing MSB agar are substituted for the actual culturing of the saliva on the MSB agar medium ${ }^{3 n}$. The MSB medium. which has been used in most of the studies. maly underestimate the actual numbers of mutans streptococci in the sample. We found that a dilute trypticase yeast extract medium containing $20 \%$ sucrose (MM10 sucrose) would routinely yield higher counts of the mutans streptococci than the MSB medium ${ }^{37}$. Subsequently, we improved this medium by adding metronidazole to inhibit anaerobic organisms ${ }^{22}$. Van Palenstein-Helderman et al., showed that the TYCSB medium was superior to the MSB medium in isolating the mutans streptococci from salivi ${ }^{23}$. In the present study, we found the TYCSB medium to be statistically superior to the metronidazole medium.

The convenience of the salivary cultures and the availability of the kits have allowed bacteriological data to be collected from many epidemiological studies, that probably would not have included culturing of plaque samples on nonselective media, i.e., the 'gold' standard. The fact that so many of these studies in the elderly have identified the mutans streptococci as a risk factor for decay indicates the usefulness of these cultures s.3.5.24.31. $^{2}$. The question then becomes, can bacteriological data obtained with this method be made more reliable? Our previous report showed that the salivary levels of the mutans streptococci were significantly related to the number of teeth $(p=0.0001)^{10}$. The importance of number of teeth is consistent with the fact that the teeth are the preferred oral surfaces for the mutans streptococci to colonize 1 . By including the number of teeth in our statistical models as a co-variable, this raised the possibility that this factor could have overwhelmed any association between the mutans streptococci and dental decay. For example, an individual with 25 teeth and no decay could have more mutans streptococci per ml saliva than an individual with 5 teeth and three decayed surfaces.

In the present investigation we addressed this concern by dividing the levels of S. mutans per $\mathrm{ml}$ of saliva by the number of teeth present in the dentition, and found the resulting value, i.e., CFUs/ $\mathrm{ml} /$ tooth, to be an independent risk factor for the presence of any decay and the presence of coronal surface decay (Tables 4 and 5). The odds ratio in each case would be interpreted as a $12 \%$ increase in the odds for decay for each unit increase of log CFUs/ml saliva per tooth. The same considerations would apply to the lactobacilli counts (Table 7). The lactobacilli and not $S$. mutans were associated with root surface decay in the multivariable analysis (Table 6). This disagrees with previous reports, which implicated $S$. mutans in root surface decay 31.4 , but is in agreement with many studies that implicate the lactobacilli ${ }^{7}, 0,27,24,31,35$.

The yeasts were not associated with either coronal surface or root surface decay in these models. although they were significantly associated with decay in the bivariate analysis (Table 3), and in our previous multivariable model in which the microbial counts were reported as CFUs per ml saliva ${ }^{10}$. Others have associated the yeasts with root surface decay in the elderly ${ }^{7}$, and as predictors of root surface decay in older individuals ${ }^{9}$, and coronal decay in young individuals ${ }^{38}$. The salivary levels of yeasts are increased in the presence of dentures ${ }^{10.16 .17}$, so that this factor needs to be accounted for in assessing any role of yeast in the etiology of caries. As the levels of yeast are usually 1 to $2 \log$ units less than those of the mutans streptococci and lactobacilli, Beighton and Lynch have suggested that the yeast, because of their aciduricity, may serve as a marker organism for active root caries ${ }^{39}$.

These models (Table 7) indicate that salivary $S$. mutans and lactobacilli levels, when calculated on a per tooth basis, are significant risk predictors for decay in the elderly. The $S$. mutans counts are specific for coronal surface decay, whereas the lactobacilli are specific for root surface decay. When these bacteriological variables are combined with the other significant risk factors, it is possible to distinguish whether the subject is at risk for either coronal surface decay or for root surface decay. Thus, individuals residing in a dependentliving situation were 4.5 times more likely to have coronal surface decay compared to those in an independent living situation. If individuals also had elevated $S$. mutans levels and were white males, the odds of having caries would increase still further. The odds for root surface caries are greater in males wearing any kind of denture who have high lactobacilli levels, and would increase with age.

Other investigators have shown that a dependentliving status is a risk factor for decay ${ }^{13}$, but in our convenience sample, this risk was associated with coronal surface decay, and did not apply to root surface decay. Elderly black subjects were 2.4 times less likely to have any decay, and 2.94 times 
less likely to have coronal surface decay than were elderly white subjects (Table 7). This is contrary to the US national data reported in the NHANES III study ${ }^{40}$, in which Non-Hispanic blacks had more decayed coronal surfaces than Non-Hispanic whites, and could reflect the convenience nature of our sample population.

Females were less likely to have any type of decay than males after controlling for other factors (Table 7). This is in agreement with the NHANES III data in which females $\geq 65$ years tended to have fewer decayed surfaces than males of the same age $^{40}$. However, other factors were operating in our female population that could contribute to this finding. Many of the females were residents of a private retirement community, had a high social economic status, and exhibited a higher than usual level of dental health in that they had a low edentulous rate, i.e. $6 \%$, and an average of 23 teeth per individual ${ }^{41}$. The comparable data for similaraged females in the NHANES III survey showed an edentulous rate of about 30 to $40 \%$ and the presence of 16 to 19 teeth $^{40}$.

While dental decay has long been known to be multifactorial, it has only been recently that statistical programs have allowed simultaneous analysis of these factors in multivariable models. The actual definition of the bacterial factors is one of continued refinement. This is particularly true when using salivary CFUs as a surrogate for the actual levels of the cariogenic species in the plaque over or within the lesion. In the present investigation these salivary levels were adjusted for the number of teeth in the dentition, and this adjustment resulted in $S$. mutans being associated with coronal surface decay and lactobacilli with root surface decay, but the yeastS could not be associated with any type of decay. This construct of reporting salivary bacteriological data as a function of tooth number and per $\mathrm{ml}$ saliva could improve the reliability of bacteriological data obtained in epidemiological studies investigating the role of bacteria in dental decay in the elderly.

\section{Acknowledgments}

This investigation is supported by a USPH Research grant DE-09142 from the National Institute of Dental Research, and IP30-AG-008808 from the National Institutes of Health, Bethesda, MD 20892. Walter Bretz, Kathy Curry and Gary Hildebrandt assisted in the collection of the dental data and Bonnie Hartsuff and Yin-Maio Chen assisted in the statistical analysis. Carol Gerlach assisted in the preparation of the manuscript.

\section{References}

1. Loesche W J. Role of Streptococcus mutans in human dental decay. Microbiol Reviews 1986; 50: 353-380.

2. Emilson C G, Thorselius I. Prevalence of mutans streptococici and lactobacilli in elderly Swedish individuals. Scand J Dent Res 1988; 96:14-21.

3. Fure S, Zickert I. Salivary conditions and cariogenic microorganisms in 55, 65, and 75-yearold Swedish individuals. Scand J Dent Res 1990; 98: 197-210.

4. Kohler B, Persson M. Salivary levels of mutans streptococci and lactobacilli in dentate 80and 85-year-old Swedish men and women. Community Dent Oral Epidemiol 1991; 19: $352-356$.

5. Hunt R J, Drake C W, Beck J D. Streptococcus mutans, lactobacilli and caries experience in older adults. Spec Care Dentist 1992; 12:149-152.

6. Nahri T O, Ainamo A, Meurman $\mathbf{J} \mathbf{H}$. Mutans streptococci and lactobacilli in the elderly. Scand J Dent Res 1994; 102:97-102.

7. Beighton D, Hellyer P H, Lynch E J, et al. Salivary levels of mutans streptococci, lactobacilli, yeasts, and root caries prevalence in noninstitutionalized elderly dental patients. Community Dent Oral Epidemiol 1991; 19: 302-307.

8. Nahri T O, Ainamo A, Meurman $\mathbf{J} \mathbf{H}$. Salivary yeast, saliva and oral mucosa in the elderly. J Dent Res 1993; 72:1009-1014.

9. Scheinin A, Pienihakkinen K, Tiekso J, et al. Multifactoral modeling for root caries prediction: 3-year follow-up results. Community Dent Oral Epidemiol 1994; 22:126-129.

10. Loesche W J, Schork A, Terpenning M T, et al. Factors which influence levels of selected organisms in saliva of older individuals. $J$ Clin Microbiol 1995; 33: 2550-2557.

11. Narhi T O, Meurman J H, Ainamo A, et al. Association between salivary flow rate and the use of systemic medication among 76-, 81-, and 86-year-old inhabitants in Helsinki, Finland. J Dent Res 1992; 71:1875-1880

12. Loesche $\mathbf{W} \mathbf{J}$, Bromberg $\mathbf{J}$, Terpenning et al. Xerostomia, xerogenic medications and food avoidances in selected geriatric groups. JAmer Ger Soc 1995; 43:401-407.

13. Berkey D B. Berg R G, Ettinger D L, et al. Research review of oral health status and service use among institutionalized older adults in the United States and Canada. Spec Care Dent 1991; 11:131-136. 
14. Klock B, Svanberg M, Petersson I, G. Dental cintics, mutans streptococci, lactobacilli, and saliva secretion rate in adults. Community Dent Oral Epidemiol 1990; 18:249-252

15. Salonen L, Allander 1, Bratthall D, et al. Mutans streptococci, oral hygiene, and caries in an adult Swedish population. J Dent Re's 1990; 69:1469-1475.

16. Kreher J M, Graser G N, Handelman S L, et al. Oral yeasts, mucosal health, and drug use in an elderly denture wearing population. Spec Care I'ntist 1991: 11: 222-226.

17. Marsh P D, Percival R S, Challacombe S $\mathbf{J}$. The influence of denture-wearing and age on the oral microflora. J Dent Res 1992; 71:13741381 .

18. Ship J A, Fox P C, Baum B J. How much silic a is enough"? "Normal" function defined. $J \mathrm{Am}$ Dent Assoc 1991; 122:63-69.

19. Miller A J, Brunelle J A, Carlos J P, et al. Oral health of United States adults. National Institute of Health. DHHS Pub No. 87-2868, 1987.

20. Mandel I D. Sialochemistry in diseases and clinical situations affecting salivary glands. Crit Rev Clin Lab Sci 1980; 12:321-366

21. Fox P C, Busch K A, Baum B J. Subjective reports of xerostomia and objective measures of salivary gland performance. JAm Dent Assoc 1987; 115:581-.584

22. Loesche W J, Syed S A, Schmidt E, et al. Bacterial profiles of subgingival plaques in periodontitis. J Periodontol 1985; 56:447-456.

23. Van Palenstein-Helderman W H, Ijsseldijk M, Huis In't Veld J H. A selective medium for the two major subgroups of the bacterium Streptococilis mutans isolated from human dental plaque and saliva. Arch Oral Biol 1983; 28:599. 603.

24. Hollander $\mathbf{M}$, Wolfe D. Nonparametric Statistical Methods. John Wiley \& Sons, NY. 1973.

25. Neter J, Wasserman W, Kutner M. Applied Linear Statistical Models 3rd ed. Irwin Publ., Homewood, IL. 1990.

26 Zickert I, Emilson C, Krasse B. Streptococcus mutans, lactobacilli and dental health in 13-14-year-old Swedish children . Community Dent Oral Epidemiol 1982; 9:182-190.

27. MacEntee M I, Clark D C, Glick N. Predictors of caries in old age. Gerodontolog! 1993; 10:80-97.

28. Drake C W, Beck J D, Lawrence H P, et al. Three-year coronal caries incidence and risk factors in North Carolina elderly. Carie's Res 1997; $31: 1$ 7.

29. Lundgren M, Emilson C G, Osterberg T, et al. Dental caries and related factors in 88- and 92-year-olds. Cross-sectional and longitudinal comparisons. Acta Odontol. Scand 1997; 55:282291.
30. Powell L V, Leroux B G, Persson R E, et al. Factors associated with caries incidence in an elderly population. Comm. Dent. Oral Epidemiol 1998; 26:170-176.

31. Fure S. Five year incidence of caries, salivary and microbial conditions in 60-, 70- and 80- yearold Swedish individuals. Caries Res 1998; 32:166174.

32 Lundgren M, Emilson C G, Osterberg T. Caries prevalence and salivary and microbial conditions in 88-year-old Swedish dentate people. Acta Odontol. Scand. 1996; 54:193-199.

33. Dasanayake A P, Caufield P W, Cutter G $\mathbf{R}$, et $\boldsymbol{a l}$. Differences in the detection and enumeration of mutans streptococci due to differences in methods. Arch of Oral Biol 1995; 40:345-351.

34. Loesche W J, Rowan J, Straffon $\mathbf{L} \mathbf{H}$ et al. The association of Streptococcus mutans with human dental decay. Infect Immun 1975; 11:12521260.

35. Beighton D, Lynch E. Comparison of selected microflora of plaque and underlying carious dentine associated with primary root caries lesions. Caries Res 1995; 29:154-158.

36. Davenport E S, Day S, Hardie J M, et al. A comparison between commercial kits and conventional methods for enumeration of salivary mutans streptococci and lactobacilli. Comm Dent Health 1992; 9: 261-271.

37. Loesche W J, Bradbury D R, Woolfolk M P. Reduction of dental decay in rampant caries individuals following short term Kanamycin treatment. J Dent Res 1977; 56:254-265.

38. Raitio M, Pienihakkinen K, Scheinin A. Multifactorial modeling for prediction of caries increment in adolescents. Acta Odontol. Scand. 1996: 54:118-121.

39. Beighton D, Lynch E. Relationships between yeasts and primary root-caries lesions. Gerodontology' 1993; 10:105-108.

40. Winn D M, Brunelle J A, Selwitz, R H, et al. Coronal and root caries in the dentition of adults in the United States, 1988-1991. J Dent Res 75 sp. Issue:642-651.

41. Loesche W J, Abrams J, Terpenning M S, et al. Dental findings in geriatric populations with diverse medical backgrounds. Oral Med Oral Surg Oral Path 1995; 80: $43-54$

Address for correspondence:

Professor WJ Loesche,

University of Michigan School of Dentistry,

1011 N. University, Ann Arbor.

Michigan 48109-1078, USA

Tel: +1 (7.34) 764-8386 Fax +1 (734) 764-7406;

e-mail:wloesche@umich.edu 
This document is a scanned copy of a printed document. No warranty is given about the accuracy of the copy. Users should refer to the original published version of the material. 